\title{
EON
}

\section{Taming Technology: Navigating EON's New Platform}

\section{Lindsey Brounstein 1}

${ }^{1}$ Director of Publications, American Gastroenterological Association

Published on: Dec 27, 2021

License: Creative Commons Attribution 4.0 International License (CC-BY 4.0). 


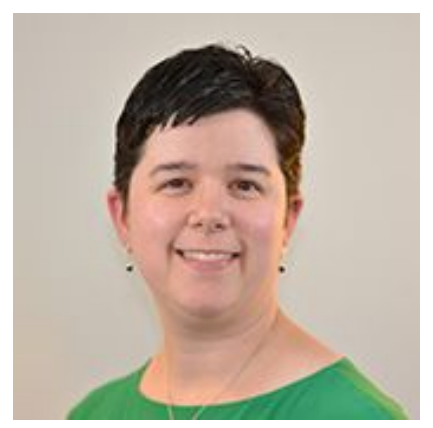

Lindsey

Brounstein

Director of

Publications,

American

Gastroenterological

Association

Co-Editor-in-Chief,

EON

As you know, EON has moved to a new publication platformyou can see our message from the editors from the November 2021 issue for details on the how and why. In light of this move, I wanted to take this opportunity to highlight some of the key features of our new platform to ensure that you, our readers, can get the most out of your experience.

\section{Current and Past Issues}

In addition to the link arriving in your inbox each month, if you point your browser toward eon.pubpub.org, you can click on "Latest Issue" to be taken to the articles, and you'll also see the full table of contents right on the main page (Figure $1)$.

If you're looking for past issues, those can be found by clicking on the "All Issues" button at the top (Figure 2), or by scrolling down until you get to the "Past Issues" header on the main page (Figure 3).

Please note that any issues older than September 2021 are still housed on ISMTE's website, so the links to older issues will redirect to those archives, where any articles more than two years old will be freely available.
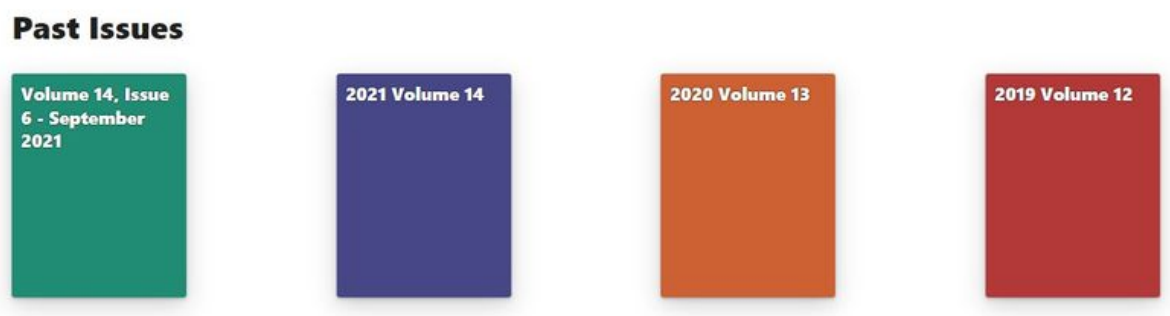

See all archived issues $>>$

Figure 3. "Past Issues" section on the main page. The previous four issues will display here, along with a link to connect to the full issue archives. 


\section{Article Features: Cite, Social, and Download}

Some of the features that we're most excited about on the new platform can be found within each article. At the top of each article, you'll see several buttons to the right of the article title (Figure 4). Among these are "Cite," "Social," and "Download."

\section{Antiracism Toolkits for Scholarly Publishing Address Long-Standing Inequities}

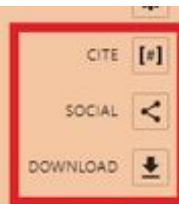

Niccole Leilanionapeaina Coggins, Jocelyn Dawson, and Damita Snow discuss the Toolkits for Equity project, and the framework it provides for scholarly publishing to address some issues which are still pervasive with scholarly publishing.

by Niccole Leilanionapaeaina Coggins, Jocelyn Dawson, and Damita Snow. CAE

Figure 4. Buttons that let you cite the article, share it to social media, or download a copy to read later.

The "Cite" button shows you how to cite the article you're reading and allows you to copy the citation (Figure 5). The "More Cite Options" link opens a new window that provides the article citation in several style formats.

The "Social" button gives you the ability to share the article via social media platforms, including Facebook and Twitter, or via email (Figure 6).

Lastly, the "Download" button allows you to download a copy of Scholarly Publishing s Inequ

Cite as

Coggins NL, Dawson J, Snow, CAE D. Antiracism Toolkits for Scholarly Publishing Address Long-Standing Inequities. EON. Published online November 17, 2021. ita Snow discuss 1 https://eon.pubpub.org/pub/glfphc53 ne issues which ar $\quad$ Copy ... More Cite Options

Figure 5. A view of the article's citation after clicking on the "Cite" button at the top right of the article header. the article to save for later, or to take with you on another device, such as an e-reader (Figure 7). You can download articles in PDF, Word document, or EPUB formats, among others.

\section{Leave a Comment}

Lastly, readers can now leave comments on all EON articles posted on the new platform (Figure 8). We hope this feature will provide a place for curiosity, discourse, 
and encouragement. Have a question? Read an article you really liked? Leave a comment!

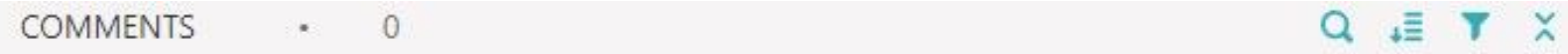

\section{Post Discussion}

Figure 8. The comment box can be found at the very bottom of every EON article. As you can see, there are many features available as part of $E O N^{p}$ s new platform. We hope you are as excited about some of these features as we are (though I doubt it... we're pretty excited...).

What did you think of this article? Leave me a comment below.

\section{Disclosure Statement}

The author has no conflicts of interest to disclose. 